\title{
Bioremediation of Lead(II) from Polluted Wastewaters Employing Sulphuric Acid Treated Maize Tassel Biomass
}

\author{
Mambo Moyo, Linda Chikazaza \\ Department of Chemical Technology, Midlands State University, Gweru, Zimbabwe \\ Email: moyom@msu.ac.zw
}

Received September 30, 2013; revised October 29, 2013; accepted November 15, 2013

Copyright (C) 2013 Mambo Moyo, Linda Chikazaza. This is an open access article distributed under the Creative Commons Attribution License, which permits unrestricted use, distribution, and reproduction in any medium, provided the original work is properly cited.

\begin{abstract}
The ability to modify a waste by-product precursor, maize tassel biomass using sulfuric acid as the activating agent with specific focus on Lead(II) ion from water has been proposed. The treating of maize tassel using sulphuric acid is believed to enhance sorption capacity of Lead(II) ions. For this, batch adsorption mode was adopted for which the effects of initial $\mathrm{pH}$, adsorbent dosage, contact time and initial concentration were investigated. Consequently, it was found that the adsorbent capacity depends on $\mathrm{pH}$; since it increases up to 4.5 and then decreases. The highest percentage of Lead(II) ion removal was achieved in the adsorbent dosage of $1.2 \mathrm{~g}$ and at an initial concentration of $10 \mathrm{mg} / \mathrm{L} \mathrm{metal} \mathrm{ion.} \mathrm{In} \mathrm{an}$ attempt to determine the capacity and rate of Lead(II) removal, isotherm and kinetic data were modeled using appropriate equations. To this end, the adsorption data fitted best into the Langmuir model with an $\mathrm{R}^{2}(0.9997)$ while kinetically the Lead(II) adsorption followed the pseudo-second-order model. Furthermore, as a way to address issues related to sustainability, maize tassel is recommended since the process is considered to be a dual solution for environmental cleaning. From one side, it represents a better way to dispose the maize tassel which has no use after fertilization and on the other hand it is an economic source of carbonaceous materials.
\end{abstract}

Keywords: Maize Tassel; Adsorption; Removal; Wastewater Treatment, Lead(II) Ion

\section{Introduction}

The presence of heavy metals in the environment poses a serious and complex environmental and public problem due to their non-degradability [1]. Among the heavy metals, Lead $(\mathrm{Pb})$ is very toxic because it is carcinogenic in nature [2]. Lead is the most significant toxin of the trace metal ions, and human exposure is through ingestion of food and water, and inhalation. Lead affects mainly the peripheral nervous system and hematopoietic, renal, gastrointestinal, cardiovascular and reproductive systems. According to World Health Organization [3], the permissible level for $\mathrm{Pb}$ in drinking water is $0.05 \mathrm{mg} / \mathrm{L}$. Consequently, the occurrence of very low concentration levels of lead in drinking water is considered as highly toxic and requires more efficient removal, extraction, and treatment methodologies.

The removal of metals from water has been previously achieved by various methods such as ion exchange, precipitation, oxidation, reduction and membrane filtration $[4,5]$. Currently, adsorption technology using cheap, eas- ily available agricultural plants, algal biomass and cyanobacteria has increased in recent years. However, the use of raw sorbents in adsorption may cause problems since most plants contain a green pigment known as chlorophyll (sparingly soluble in water) and some organic matter may be leached out, consequently affecting the taste and colour of the treated waters [6,7]. In spite of the versatility of commercial activated carbon as an adsorbent in wastewater treatment with its high surface area, microporous characteristics, and high adsorption capacity; its high cost and loss during the regeneration restrict its applications in developing countries [8,9]. Given these disadvantages, efforts have now been geared towards introducing low cost precursors that can serve as alternative sources for water cleaning after modification using different activation agents. In the recent years, modified sorbents derived from locally available materials such as Ceiba pentandra hulls [8], Euphorbia rigida [10], hazelnut husks [11], wheat bran [12], coirpith [13], and coconut shell [14] have received increasing attention for the removal and recovery of heavy metals from water 
and wastewater systems.

Maize tassel is an inexhaustible, non-edible, mesoporous and renewable polymeric material resource, which is discarded as waste by most farmers after fertilization [15]. Hence, the present study aims to assess the applicability of acid treated maize tassel for the adsorptive removal of Lead(II) from aqueous solution and to investigate the effect of operating parameters on the adsorption process. The parameters studied include contact time, initial Lead(II) concentration, adsorbent dosage and initial solution $\mathrm{pH}$.

\section{Materials and Methods}

\subsection{Modification of Maize Tassel}

The maize tassel was collected from Morris farm in Northlea, Gweru, Zimbabwe. Maize tassel was plucked off the woody parts of the maize plant, thoroughly washed with water and sun dried for 5 days. The dry biomass was milled and then fractionated using $100-300 \mu \mathrm{m}$ analytical sieves. Then, the modification was prepared according to reported procedure [16-18]. Briefly, the fractionated maize tassel powder $(200 \mathrm{~g})$ was weighed in a clean dry beaker of capacity $1 \mathrm{~L}$ containing $(200 \mathrm{~mL}$, $97 \% \mathrm{H}_{2} \mathrm{SO}_{4}$ for $24 \mathrm{~h}$ ) followed by refluxing in a fume hood for $4 \mathrm{~h}$. After cooling, the reaction mixture was filtered, and the filtrate was washed repeatedly with ultra-pure water and soaked in $1 \% \mathrm{NaHCO}_{3}$ solution to remove any remaining acid. The sample was then washed with distilled water until the $\mathrm{pH}$ of the acid treated maize tassel was between $6-7$, dried in an oven at $120^{\circ} \mathrm{C}$ overnight and kept in a glass bottle until use.

\subsection{Characterization of Prepared Acid Treated Maize Tassel}

The bulk density, loss of mass on ignition, simple specific surface area, $\mathrm{pH}$ and moisture content of the acid treated maize tassel were determined following reported procedures $[19,20]$. Briefly, for bulk density, acid treated maize tassel was transferred to a $10 \mathrm{~mL}$ measuring cylinder of about $1.0 \mathrm{~cm}$ diameter. Sufficient quantity of powder was added to occupy a volume of $10 \mathrm{~mL}$ under the condition, and it was subsequently weighed. The bulk density was expressed as grams per litre (the weight of the acid treated maize tassel filling a graduated cylinder on gentle tapping, divided by the volume of the cylinder $10 \mathrm{~mL}$ ). The loss of mass on ignition was done by weighing $15 \mathrm{~g}$ of the acid treated maize tassel and put inside furnace at constant temperature of $600^{\circ} \mathrm{C}$ for $2 \mathrm{~h}$. After roasting, the sample became charred and was removed from the furnace then put in a desiccator for cooling. The residual product was then weighed, and the difference in mass represented the mass of organic material present in the sample. For moisture content, $10 \mathrm{~g}$ of acid treated maize tassel was weighed into a crucible and heated in the oven for $5 \mathrm{~h}$ at constant temperature of $105^{\circ} \mathrm{C}$. The sample was then removed and put in a desiccator in so that moisture from atmosphere could not be absorbed. The sample was reweighed. This procedure was repeated several times until a constant weight was obtained. The difference in the mass constitutes the amount of moisture content of the adsorbent

$$
\% \text { moisture }=\left(w_{2}-w_{3}\right) /\left(w_{2}-w_{1}\right) \times 100
$$

where $w$

$w_{1}$ is weight of crucible,

$w_{2}$ is initial weight of crucible with sample,

$w_{3}$ is final weight of crucible with sample.

\subsection{Preparation of Synthetic Solution}

A stock solution of Lead(II) ion (1000 mg/L) was prepared by dissolving $\mathrm{Pb}\left(\mathrm{NO}_{3}\right)_{2}$ (Merck, South Africa) in ultra-pure water (resistivity $>18 \mathrm{M} \Omega \cdot \mathrm{cm}^{-1}$ ). The progressive dilution procedure of the stock solution was employed in the preparation of working solutions. The $\mathrm{pH}$ of the working solutions was adjusted to the required value with $0.1 \mathrm{M} \cdot \mathrm{NaOH}$ or $0.1 \mathrm{M} \cdot \mathrm{HCl}$. All the chemicals used were of analytical reagent grade.

\subsection{Batch Adsorption Studies}

A weighed amount of acid treated maize tassel was introduced into stoppered reagent bottles containing various concentrations with $100 \mathrm{~mL}$ aqueous solutions of Lead(II) ions. The suspensions were shaken at room temperature $\left(25^{\circ} \mathrm{C} \pm 1^{\circ} \mathrm{C}\right)$ using a mechanical shaker for a prescribed time at $160 \mathrm{rpm}$. The solutions were filtered through Whatman 42 filter paper and the residual concentration of metal ion was determined by AAS method. The effects of concentration $(10-50 \mathrm{mg} / \mathrm{L})$, contact time (5 - $300 \mathrm{~min})$, solution $\mathrm{pH}(2-12)$ and adsorption dose $(0.1-2.5 \mathrm{~g})$ were studied. The percentage of removed Lead(II) ions $(R \%)$ in solution was calculated by using Equation (2):

$$
R \%=\frac{\left(C_{i}-C_{e}\right) 100}{C_{i}}
$$

The amount of metal adsorbed by acid treated maize tassel was calculated from the difference between metal quantity added to the biomass and metal content of the supernatant using Equation (3):

$$
q_{e}=\frac{\left(C_{i}-C_{e}\right) V}{M}
$$

where $q_{e}$ is the metal uptake (mg metal adsorbed per $g$ adsorbent), $C_{i}$ and $C_{e}$ are the initial and equilibrium metal concentration in solution $(\mathrm{mg} / \mathrm{L}), V$ is the volume of the solution $(\mathrm{mL})$ and $M$ is the weight of acid treated maize 
tassel (g).

\subsection{Desorption Studies}

For the desorption studies, contact was made between 1.2 $\mathrm{g}$ of acid treated maize tassel and a $100 \mathrm{~mL}$ Lead(II) solution. After Lead(II) ion sorption, the acid treated maize tassel was filtered, washed three times with ultra-pure water to remove residual Lead(II) ions on the surface, and kept in contact with different concentrations $(0.05$ $0.3 \mathrm{~mol} / \mathrm{L}$ ) of $100 \mathrm{~mL} \cdot \mathrm{HCl}$ solution. The mixtures were shaken in a rotary shaker for $60 \mathrm{~min}$. The filtrates were analyzed to determine the concentration of Lead(II) ions after desorption using AAS.

\subsection{Adsorption Isotherms}

In the present study, the equilibrium data for the adsorbed Lead(II) ions onto acid treated maize tassel was expressed using Langmuir and Freundlich isotherm. The Freundlich isotherm [21] is given by Equation (4):

$$
q_{e}=K_{F} C_{e}^{1 / n}
$$

The parameters can be linearized by taking logarithms to find the parameters $K_{F}$ and $n$ :

$$
\ln q_{e}-\ln K_{F}+\frac{1}{n} \ln C_{e}
$$

A plot of $\ln q_{e}$ versus $\ln C_{e}$ gives a straight line and $K_{F}$ and $n$ can be calculated from the intercept and slope, respectively. The linear form of the Langmuir isotherm model [22] can be represented by Equation (6):

$$
\frac{1}{q_{e}}=\frac{1}{q_{\max }}+\left(\frac{1}{b q_{\max }}\right) \frac{1}{C_{e}}
$$

A plot of $1 / q_{e}$ versus $1 / C_{e}$ was found to be a straight line with $1 / q_{\max }$ as intercept and $1 / q_{\max } b$ as slope and hence $q_{\max }$ and $b$ can be calculated. In addition, a dimensionless constant called separation factor, $R_{L}$ can be used to express an essential feature of Langmuir isotherm [23]:

$$
R_{L}=\frac{1}{1+a C_{m}}
$$

where, $C_{m}$ is the initial concentration of Lead(II). The value of $R_{L}$ indicates the type of the isotherm to be either unfavorable when $R_{L}>1$, linear if $R_{L}=1$, favorable if 0 $<R_{L}<1$ or $R_{L}=0$.

\subsection{Adsorption Kinetics}

The pseudo-second order model has been widely used for adsorption for the following reasons: it does not have the problem of assigning an effective adsorption capacity, the adsorption constant capacity, rate constant and initial adsorption rate can all be determined from the equation without knowing any parameter beforehand [24]. Hence in the present study, adsorption of Lead(II) ions on acid treated maize tassel has been described by pseudo-second-order model [18]. The general form of the pseudosecond-order kinetic model:

$$
\frac{t}{q_{t}} \frac{1}{k_{2} q_{e}^{2}}+\frac{1}{q_{e}} t
$$

where $q_{e}$ and $q_{t}(\mathrm{mg} / \mathrm{g})$ are the amounts of the Lead(II) ions sorbed at equilibrium and at time $t(\mathrm{~min})$, respectively and $k_{2}(\mathrm{mg} / \mathrm{g} \cdot \mathrm{min})$ is the second order rate constant. The slope of the plot $\left(t / q_{t}\right)$ versus $t$ gives the value of $q_{e}$ and from the intercept $k_{2}$ can be calculated

\section{Results and Discussion}

\subsection{Physicochemical Characteristics of Acid Treated Maize Tassel}

The physico-chemical characteristics like $\mathrm{pH}$, moisture content, bulk density, surface area, and loss of mass on ignition were determined and given in Table 1.

\subsection{Effects of Dosage}

The effect of biomass dosage on the biosorption of $\mathrm{Pb}$ (II) ions was studied using biomass dosage in the range 0.1 $2.5 \mathrm{~g}$ (Figure 1). As shown in Figure 1, the percentage removal increases sharply from $58.5 \%$ to $92.2 \%$, but beyond this, the percentage removal did not increase significantly and reached a maximum at $92.3 \%$. This phenomenon can be due to the greater availability of activity sites or surface area making easier penetration of the Lead(II) ions to the adsorption sites and increasing this number had no effect after equilibrium is reached. These results are in agreement to other results reported in literature $[2,25]$.

\subsection{Effect of pH}

The effect of initial $\mathrm{pH}$ of a solution is a major factor used to determine the adsorption property of an adsorbent from wastewater. The possible reasons are its effects on the chemistry of the ions and the activity of functional groups (carboxylate, phosphate and amino groups) on the cell walls [12]. As shown in Figure 2, there is an in-

Table 1. Characteristics of the acid treated maize tassel developed from maize tassel.

\begin{tabular}{cc}
\hline Parameter & Value \\
\hline $\mathrm{pH}$ & 6.9 \\
Moisture $(\%)$ & 0.3 \\
Bulk density $\left(\mathrm{g} \cdot \mathrm{mL}^{-1}\right)$ & 0.52 \\
Surface area $\left(\mathrm{m}^{2} / \mathrm{g}\right)$ & 250 \\
Particle size range & $100-300 \mu \mathrm{m}$ \\
\% Loss of mass on ignition & 0.7 \\
\hline
\end{tabular}




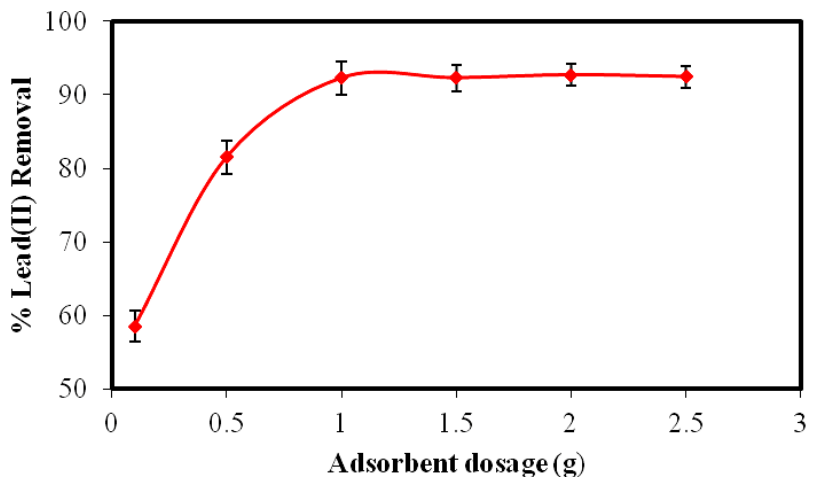

Figure 1. Dosage versus percentage removal of Lead(II) ion (contact time: $60 \mathrm{~min}$; pH 5.4; initial concentration $10 \mathrm{mg} / \mathrm{L}$; Error bar $= \pm$ S.D. and $n=3$ ).

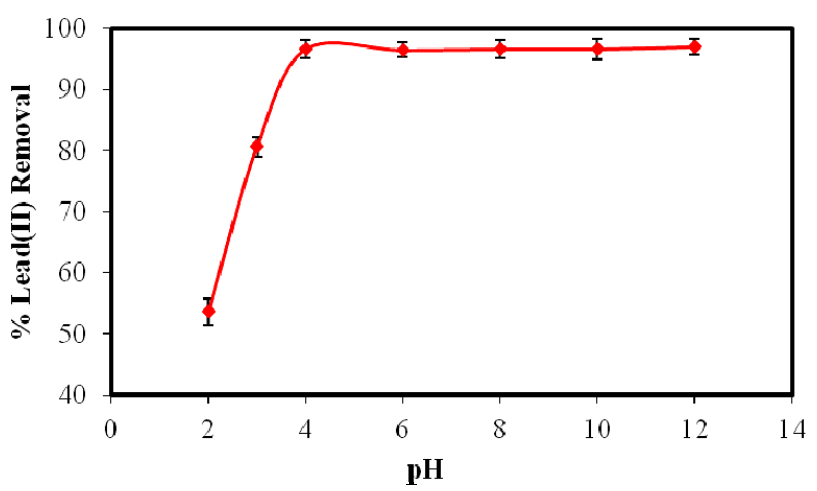

Figure 2. pH against percentage removal of Lead(II) ion (contact time: $60 \mathrm{~min}$; dosage $1.2 \mathrm{~g}$; initial concentration 10 $\mathrm{mg} / \mathrm{L}$; Error bar $= \pm$ S.D. and $n=3$ ).

crease in the quantity of adsorbed Lead(II) ions onto acid treated maize tassel by increasing $\mathrm{pH}$ of the medium up to a maximum value of $\mathrm{pH}$ 5.4. At low $\mathrm{pH}$ values, the adsorbent is positively charged since the $\mathrm{pH}$ is lower than the isoelectric point or point of zero charge (PZC) [26]. Hence the removal yield of Lead(II) ions is very low due to the electrostatic repulsion forces between positively charged $\mathrm{H}_{3} \mathrm{O}^{+}$and $\mathrm{Pb}^{2+}$ ions. Thereafter the adsorption percentage decreased in alkaline medium perhaps due to the formation of $\mathrm{Pb}(\mathrm{OH})_{2}$ and soluble hydroxyl complexes such as $\mathrm{PbOH}^{+}$, aqueous $\mathrm{Pb}(\mathrm{OH})_{2}$ and $\mathrm{Pb}(\mathrm{OH})^{3-}$ and adsorbent was deteriorated with the accumulation of metal ions making true adsorption studies impossible $[25,27]$. The results obtained in this study showed that the acid treated maize tassel is more effective in removing Lead(II) ions from an aqueous system with more than $94 \%$ removal as compared to raw maize tassel 75\% [28]; physically prepared AC 78\% [29]. Therefore, $\mathrm{pH} 5.4$ was selected to be the optimum $\mathrm{pH}$ for all further studies.

\subsection{Effect of Agitation Time and Initial Concentration}

The effect of agitation time is one of the important fac- tors when designing batch sorption systems for economical wastewater treatment plant application [13]. As shown in Figure 3, the relationship between agitation time and Lead(II) ion sorption onto acid treated maize tassel at different initial Lead(II) concentrations is determined by plotting the percentage biosorption of Lead(II) ion against agitation time for the interaction time intervals of between 2 to $300 \mathrm{~min}$.

It was observed that $52 \%, 60 \%, 65 \%$ and $70 \%$ of Lead(II) ions was removed in the first 2 min for the different concentrations 10, 20, 30 and $50 \mathrm{mg} / \mathrm{L}$ respectively and the process was rapid up to 60 min reaching $91.8 \%$. Beyond $60 \mathrm{~min}$, the percentage of biosorption is almost constant indicating the attainment of equilibrium conditions. The presence of adequate external surface area on the acid treated maize tassel may have boosted the rate of adsorption to be fast in the initial stages which was followed by a slower internal diffusion process, which maybe the rate determining step. From the observed adsorption trend of Lead(II), the binding may be through van der Waals forces of attraction present on the surface of the acid treated maize tassel. Therefore, all other experiments were conducted at an agitation time of $60 \mathrm{~min}$.

The effect of initial concentration on the percentage removal is also shown in Figure 3. The concentration range from 10 to $50 \mathrm{mg} / \mathrm{L}$ for the metal ion has been studied. The removal of Lead(II) ions by acid treated maize tassel was found to decrease with increase in initial Lead(II) concentration. The observed behavior can be attributed to the increase in the amount of Lead(II) ions to the unchanging number of available active sites on the acid treated maize tassel. Hence, more metal ions were left in solution. Thus it can be said that removal of Lead(II) ion is highly concentration dependent.

\subsection{Interference Studies}

The selectivity of the acid treated maize tassel on the adsorption efficiency of Lead(II) were studied in the

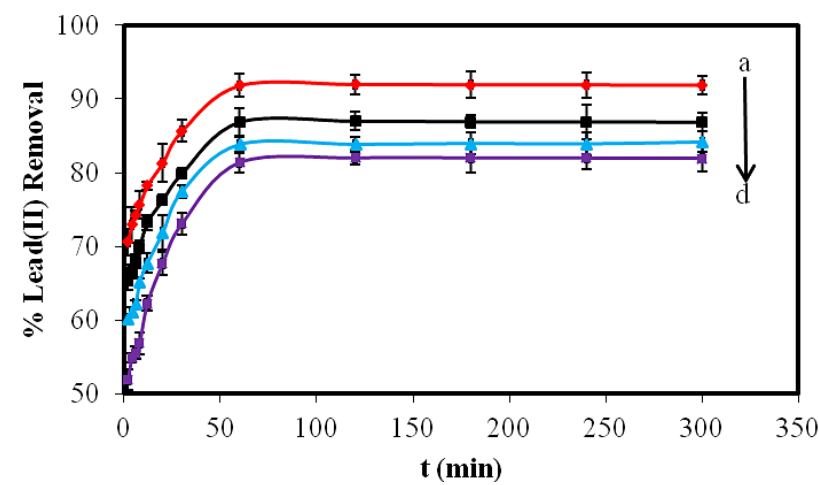

Figure 3. Agitation time against percentage removal Lead (II) ion (concentrations: a to d: 10 to $50 \mathrm{mg} / \mathrm{L}$, adsorbent dosage: $1.2 \mathrm{~g}$; pH: 5.4, Error bar $= \pm$ S.D. and $n=3$ ). 
presence of anions such as $\mathrm{F}^{-}, \mathrm{Cl}^{-}, \mathrm{NO}_{3}^{-}, \mathrm{SO}_{4}^{2-}$ and $\mathrm{PO}_{4}^{3-}$ and cations such as $\mathrm{Fe}^{2+}, \mathrm{Mg}^{2+}, \mathrm{Ca}^{2+}, \mathrm{Na}^{+}$and $\mathrm{K}^{+}$. There was no significant reduction in the adsorption of Lead(II) when the concentration of the above ions increased up to $50 \mathrm{mg} / \mathrm{L}$ in aqueous solution. It can be concluded that with proper treatment of the industrial wastewater, adsorption of Lead(II) ions on the surface of the adsorbent up to $94 \%$ in the presence of the studied anions and cations up to $50 \mathrm{mg} / \mathrm{L}$ is possible.

\subsection{Isotherm and Kinetics Study}

Figures 4(a) and (b) show the Langmuir isotherm and the Freundlich adsorption isotherm respectively. The Freundlich constants $n$ and $K_{F}$, Langmuir constants $b$ and $q_{\max }$ and the correlation coefficient $R^{2}$ are given in Table 2. The calculated value of Freundlich constant $n$ is within the range $(0.1<n<1)$, reported in literature [30] showing that adsorption is favorable. However, the linearized equation did not give a good correlation for the removal of Lead(II) onto acid treated maize tassel, indicating that Lead(II) adsorption by acid treated maize tassel fits better to the Langmuir model than to the Freundlich model. The calculated $R_{L}$ was 0.62 indicating that the adsorption of the Lead(II) was a favorable process. The plot of $t / q_{t}$ versus $t$ is shown in Figure 4(c). The values of $k_{2}$ and $q_{e}$ were $0.135 \mathrm{~g} / \mathrm{mg}$ min and $2.02 \mathrm{mg} / \mathrm{g}$ respectively. The $R^{2}$ value was 0.998 , indicating a chemisorptions process.

\subsection{Treatment of Industrial Wastewater}

The suitability of the sulphuric acid treated maize tassel for the removal of Lead(II) was tested with the leachates from an electroplating plant. The leachate sample $\mathrm{pH}$ was maintained between 5.4 - 5.9 and the determined composition of leachate from an electroplating plant is tabulated in Table 3.

The treatment of Lead(II) in leachates was significantly good $(\mathrm{p}<0.05)$. Almost $93.9 \%$ removal from wastewater was possible with $1.2 \mathrm{~g}$ of the adsorbent. Thus, the results corroborate well with what is obtained from the batch adsorption mode conducted for Lead(II) removal in synthetic wastewater samples. Furthermore, preliminary treatment of the leachates is essential before application of acid treated maize tassel as the adsorbent.

\subsection{Desorption Studies}

For wastewater treatment, the successful application of desorption reduces the dependence on thermal activation, incineration, and land disposal, which directly or indirectly increases environmental pollution. In this study, effect of $\mathrm{HCl}$ concentration on the desorption of Lead(II) ion is shown in Figure 5. It can be observed that desorption rate increases with the increase in $\mathrm{HCl}$ concentration but attained a constant at $0.2 \mathrm{M} \cdot \mathrm{HCl}$.

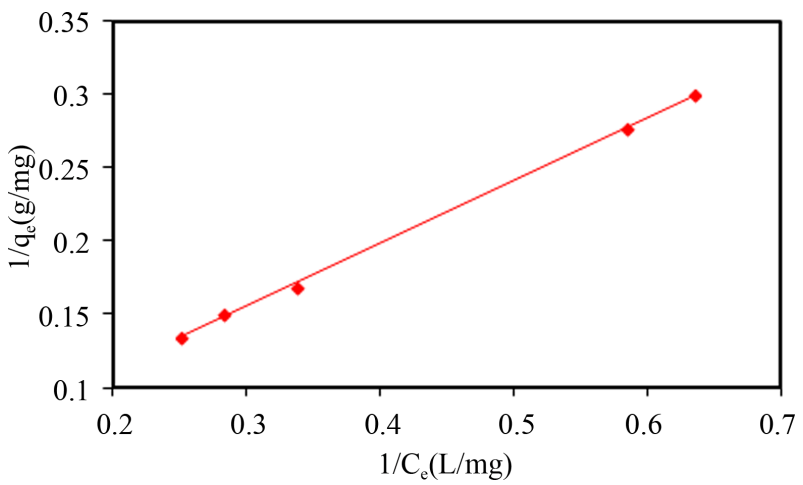

(a)

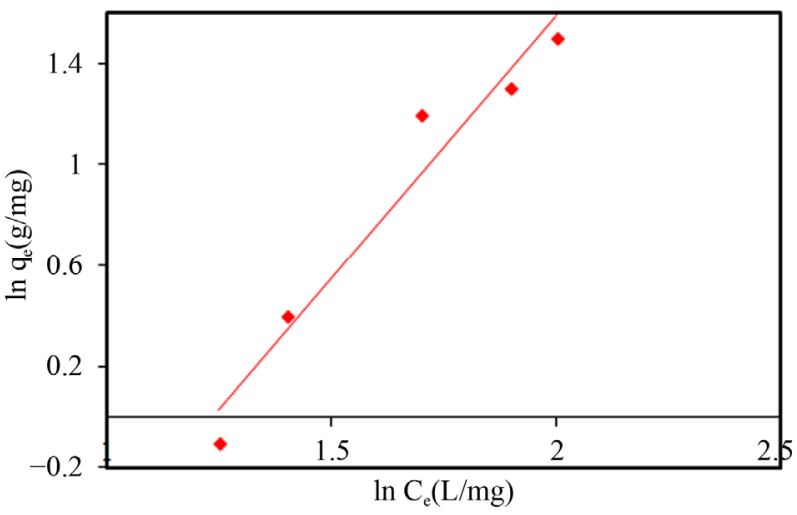

(b)

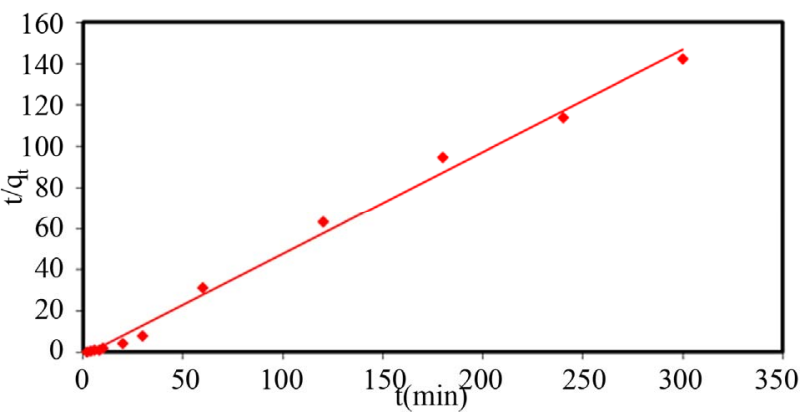

(c)

Figure 4 (a) Langmuir isotherm; (b) Freundlich isotherm for Lead(II) ion removal; (c). Pseudo-second-order kinetic fit for Lead(II) adsorption.

Table 2. Langmuir and Freundlich constants for Lead(II) adsorption using acid treated maize tassel.

\begin{tabular}{ccc}
\hline Adsorption isotherm & Parameter & Value \\
\hline Langmuir & $q_{\max }(\mathrm{mg} / \mathrm{g})$ & 37.31 \\
& $b(\mathrm{~L} / \mathrm{mg})$ & 0.062 \\
& $R^{2}$ & 0.9997 \\
Freundlich & $K_{F}$ & 0.077 \\
& $n$ & 0.482 \\
& $R^{2}$ & 0.9515 \\
\hline
\end{tabular}

\section{Conclusion}

The present study showed that acid treated maize tassel can be used for the effective removal of Lead(II) ions 
Table 3. Composition of leachates sample from an electroplating plant.

\begin{tabular}{cc}
\hline Parameter & Value \\
\hline $\mathrm{pH}$ & 3.9 \\
Total dissolved salts $(\mathrm{mg} / \mathrm{L})$ & 5056.44 \\
Turbidity $(\mathrm{NTU})$ & 1.22 \\
Electrochemical conductivity $(\mu \mathrm{mhos} / \mathrm{cm})$ & 3044.28 \\
COD $(\mathrm{mg} / \mathrm{L})$ & 30.56 \\
Chloride $(\mathrm{mg} / \mathrm{L})$ & 320.58 \\
Sulphate $(\mathrm{mg} / \mathrm{L})$ & 1005.56 \\
Calcium $(\mathrm{mg} / \mathrm{L})$ & 95.35 \\
Lead $(\mathrm{mg} / \mathrm{L})$ & 98.28 \\
Zinc $(\mathrm{mg} / \mathrm{L})$ & 18.25 \\
\hline
\end{tabular}

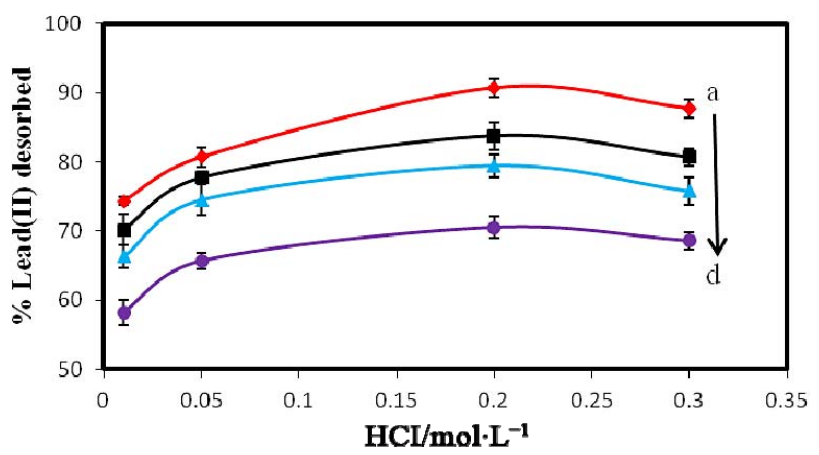

Figure 5. Effect of different $\mathrm{HCl}$ concentrations on desorption of Lead(II) ion (concentrations: a to d: 10 to $50 \mathrm{mg} / \mathrm{L}$ Error bar $= \pm$ S.D. and $n=3)$.

from wastewater. Lead(II) adsorption was found to be $\mathrm{pH}$ dependent and maximum removal was observed at $\mathrm{pH}$ 5.4. An increase in the acid treated maize tassel dosage leads to an increase in Lead(II) ions removal due to a corresponding increase in the number of active sites. The Langmuir adsorption isotherm was demonstrated to provide the best correlation $\left(R^{2}=0.9997\right)$ for the adsorption of Lead(II) ions onto acid treated maize tassel confirming monolayer coverage. Adsorption obeyed a pseudo-second-order model. It can be concluded that the acid treated maize tassel from maize tassel adds to the global discussion of its cost-effective utilization in wastewater treatment.

\section{Acknowledgements}

The authors are grateful for the Department of Chemical Technology, Midlands State University, Gweru, Zimbabwe for providing facilities.

\section{REFERENCES}

[1] P. S. Kumar, "Adsorption of Lead(II) Ions from Simulated Wastewater Using Natural Waste: A Kinetic, Thermodynamic and Equilibrium Study," Environmental Progress \& Sustainable Energy, 2013, pp. 1-10.

[2] A. B. Dekhil, Y. Hannachi, A. Ghorbel and T. Boubaker,
"Removal of Lead and Cadmium Ions from Aqueous Solutions Using the Macroalga Caulerpa racemosa," Chemistry and Ecology, Vol. 27, No. 3, 2011, pp. 221-234. http://dx.doi.org/10.1080/02757540.2010.529077

[3] World Health Organization, "Guidelines for Drinking Water Quality," Vol. 1-2, Geneva, 1984.

[4] J. M. Lezcano, F. González, A. Ballester, M. L. Blázquez, J. A. Muñoz and C. García-Balboa, "Sorption and Desorption of $\mathrm{Cd}, \mathrm{Cu}$ and $\mathrm{Pb}$ Using Biomass from an Eutrophized Habitat in Monometallic and Bimetallic Systems," Journal of environmental management, Vol. 92, No. 10, 2011, pp. 2666-2674. http://dx.doi.org/10.1016/j.jenvman.2011.06.004

[5] A. B. Marín, J. F. Ortuño, M. I. Aguilar, V. F. Meseguer, J. Saez and M. Lloréns, "Use of Chemical Modification to Determine the Binding of $\mathrm{Cd}(\mathrm{II}), \mathrm{Zn}$ (II) and $\mathrm{Cr}$ (III) Ions by Orange Waste," Biochemical Engineering Journal, Vol. 53, No. 1, 2010, pp. 2-6. http://dx.doi.org/10.1016/j.bej.2008.12.010

[6] J. P. Chen and L. Yang, "Chemical Modification of Sargassum sp. for Prevention of Organic Leaching and Enhancement of Uptake during Metal Biosorption," Industrial \& Engineering Chemistry Research, Vol. 44, No. 26, 2005, pp. 9931-9942.

http://dx.doi.org/10.1021/ie050678t

[7] I. W. Mwangi, J. C. Ngila, and J. O. Okonkwo, "A Comparative Study of Modified and Unmodified Maize Tassels for Removal of Selected Trace Metals in Contaminated Water," Toxicological \& Environmental Chemistry, Vol. 94, No. 1, 2012, pp. 20-39. http://dx.doi.org/10.1080/02772248.2011.638636

[8] M. Madhava Rao, A. Ramesh, G. Purna Chandra Rao and K. Seshaiah, "Removal of Copper and Cadmium from the Aqueous Solutions by Activated Carbon Derived from Ceiba pentandra Hulls," Journal of Hazardous Materials, Vol. 129, No. 1, 2006, pp. 123-129.

http://dx.doi.org/10.1016/j.jhazmat.2005.08.018

[9] S. T. Ong, S. P. Yip, P. S. Keng, S. L. Lee and Y. T. Hung, "Papaya (Carica papaya) Seed as a Low-Cost Sorbent for Zinc Removal," African Journal of Agricultural Research, Vol. 7, No. 5, 2012, pp. 810-819.

[10] Ö. Gerçel and H. F. Gerçel, “Adsorption of Lead(II) Ions from Aqueous Solutions by Activated Carbon Prepared from Biomass Plant Material of Euphorbia rigida," Chemical Engineering Journal, Vol. 132, No. 1, 2007, pp. 289-297. http://dx.doi.org/10.1016/j.cej.2007.01.010

[11] M. Imamoglu and O. Tekir, "Removal of Copper(II) and Lead(II) Ions from Aqueous Solutions by Adsorption on Activated Carbon from a New Precursor Hazelnut Husks," Desalination, Vol. 228, No. 1, 2008, pp. 108-113. http://dx.doi.org/10.1016/j.desal.2007.08.011

[12] A. Özer, "Removal of $\mathrm{Pb}(\mathrm{II})$ Ions from Aqueous Solutions by Sulphuric Acid-Treated Wheat Bran," Journal of Hazardous Materials, Vol. 141, No. 3, 2007, pp. 753-761. http://dx.doi.org/10.1016/j.jhazmat.2006.07.040

[13] K. Kadirvelu and C. Namasivayam, "Activated Carbon from Coconut Coirpith as Metal Adsorbent: Adsorption of Cd(II) from Aqueous Solution," Advances in Environmental Research, Vol. 7, No. 2, 2003, pp. 471-478. 
http://dx.doi.org/10.1016/S1093-0191(02)00018-7

[14] O. S. Amuda, A. Giwa and I. A. Bello, "Removal of Heavy Metal from Industrial Wastewater Using Modified Activated Coconut Shell Carbon," Biochemical Engineering Journal, Vol. 36, No. 2, 2007, pp. 174-181. http://dx.doi.org/10.1016/j.bej.2007.02.013

[15] M. Moyo, J. O. Okonkwo and N. M. Agyei, "A Novel Hydrogen Peroxide Biosensor Based on Adsorption of Horseradish Peroxidase onto a Nanobiomaterial Composite Modified Glassy Carbon Electrode," Electroanalysis, Vol. 25, 2013, pp. 1946-1954. http://dx.doi.org/10.1002/elan.201300165

[16] A. El Nemr, A. El Sikaily, A. Khaled and O. Abdelwahab, "Removal of Toxic Chromium(VI) from Aqueous Solution by Activated Carbon Using Casuarina equisetifolia," Chemistry and Ecology, Vol. 23, No. 2, 2007, pp. 119129. http://dx.doi.org/10.1080/02757540701197754

[17] A. Esmaeili, S. Ghasemi and J. Sohrabipour, "Biosorption of Copper from Wastewater by Activated Carbon Preparation from Alga Sargassum sp," Natural Product Research, Vol. 24, No. 4, 2010, pp. 341-348. http://dx.doi.org/10.1080/14786410903064915

[18] P. S. Kumar, S. Ramalingam, R. V. Abhinaya, K. V. Thiruvengadaravi, P. Baskaralingam and S. Sivanesan, "Lead (II) Adsorption onto Sulphuric Acid Treated Cashew Nut Shell," Separation Science and Technology, Vol. 46, No. 15, 2011, pp. 2436-2449. http://dx.doi.org/10.1080/01496395.2011.590174

[19] K. Nath, S. Panchani, M. S. Bhakhar and S. Chatrola, "Preparation of Activated Carbon from Dried Pods of Prosopis cineraria with Zinc Chloride Activation for the Removal of Phenol," Environmental Science and Pollution Research, 2013, pp. 4030-4045. http://dx.doi.org/10.1007/s11356-012-1325-y

[20] A. O. Dada, J. O. Ojediran, A. P. Olalekan, "Sorption of $\mathrm{Pb}^{2+}$ from Aqueous Solution unto Modified Rice Husk: Isotherms Studies," Advances in Physical Chemistry, Vol. 2013, 2013, pp. 1-6. http://dx.doi.org/10.1155/2013/842425

[21] H. M. F. Freundlich, "Over the Adsorption in Solution," Journal of Physical Chemistry, Vol. 57, 1906, pp. 384470.

[22] I. Langmuir, "The Constitution and Fundamental Properties of Solids and Liquids. II. Liquids. 1.," Journal of the American Chemical Society, Vol. 39, No. 9, 1917, pp.
1848-1906. http://dx.doi.org/10.1021/ja02254a006

[23] K. R. Hall, L. C. Eagleton, A. Acrivos and T. Vermeulen, "Pore- and Solid-Diffusion Kinetics in Fixed-Bed Adsorption under Constant-Pattern Conditions," Industrial \& Engineering Chemistry Fundamentals, Vol. 5, No. 2, 1966, pp. 212-223.

http://dx.doi.org/10.1021/i160018a011

[24] W. Li, L. Zhang, J. Peng, N. Li, S. Zhang and S. Guo, "Tobacco Stems as a Low Cost Adsorbent for the Removal of $\mathrm{Pb}$ (II) from Wastewater: Equilibrium and $\mathrm{Ki}$ netic Studies," Industrial Crops and Products, Vol. 28, No. 3, 2008, pp. 294-302. http://dx.doi.org/10.1016/j.indcrop.2008.03.007

[25] J. Srinivasa Rao, C. Kesava Rao and G. Prabhakar, “Optimization of Biosorption Performance of Casuarina Leaf Powder for the Removal of Lead Using Central Composite Design," Journal of Environmental \& Analytical Toxicology, Vol. 3, No. 2, 2013, p. 166.

[26] I. W. Mwangi and J. C. Ngila, "Removal of Heavy Metals from Contaminated Water Using Ethylenediamine-Modified Green Seaweed Caulerpa serrulata," Physics and Chemistry of the Earth, Parts A/B/C," Vol. 50-52, 2012, pp. 111-120. http://dx.doi.org/10.1016/j.pce.2012.08.015

[27] S. Doyurum and A. Celik, "Pb(II) and $\mathrm{Cd}(\mathrm{II})$ Removal from Aqueous Solutions by Olive Cake," Journal of Hazardous Materials, Vol. 138, No. 1, 2006, pp. 22-28. http://dx.doi.org/10.1016/j.jhazmat.2006.03.071

[28] C. M. Zvinowanda, J. O. Okonkwo, M. M. Sekhula, N. M. Agyei and R. Sadiku, "Application of Maize Tassel for the Removal of $\mathrm{Pb}, \mathrm{Se}, \mathrm{Sr}, \mathrm{U}$ and $\mathrm{V}$ from Borehole Water Contaminated with Mine Wastewater in the Presence of Alkaline Metals," Journal of Hazardous Materials, Vol. 164, No. 2, 2009, pp. 884-891.

http://dx.doi.org/10.1016/j.jhazmat.2008.08.110

[29] O. F. Olorundare, R. W. M. Krause, J. O. Okonkwo and B. B. Mamba, "Potential Application of Activated Carbon from Maize Tassel for the Removal of Heavy Metals in Water," Physics and Chemistry of the Earth, Parts $A / B / C$, Vol. 50-52, 2012, pp. 104-110.

[30] C. Raji and T. S. Anirudhan, "Batch Cr(VI) Removal by Polyacrylamide-Grafted Sawdust: Kinetics and Thermodynamics," Water Research, Vol. 32, No. 12, 1998, pp. 3772-3780. http://dx.doi.org/10.1016/S0043-1354(98)00150-X 